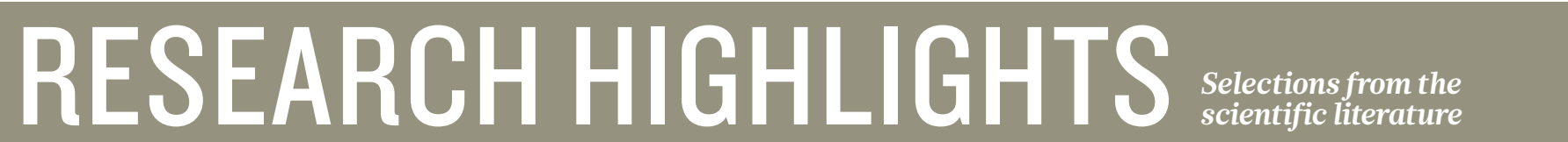

NEUROSCIENCE

\section{Pups' smell tunes mum's hearing}

The smell of their pups alters the neural responses of lactating female mice, making the mothers more sensitive to pup sounds.

Adi Mizrahi and his colleagues at the Hebrew University of Jerusalem in Israel recorded the activity of single neurons in the primary auditory cortex of female mice. They found a more variable neuronal firing rate in lactating mothers exposed to pup odours than in lactating animals exposed to nesting materials or in virgin females. In an experimental test of maternal behaviour, both mothers and virgins with experience of pups responded to the cries of pups that had strayed from the nest and retrieved them, whereas naive virgins did not. Furthermore, the auditory neurons of females that had interacted with pups were more sensitive to certain pup sounds than those of naive females.

Neuron 72, 357-369 (2011)

\section{INFECTIOUS DISEASE}

\section{Antibody beats emerging virus}

A human antibody prevents disease in monkeys infected with the deadly Hendra virus. The virus, first identified in 1994, normally sickens horses, but also kills about $60 \%$ of humans who become infected.

Christopher Broder at the Uniformed Services University in Bethesda, Maryland, and his colleagues show that a human monoclonal antibody, m102.4, blocks the disease in African green monkeys. These animals provide a model in which the bloodvessel-destroying infection mirrors that in humans.

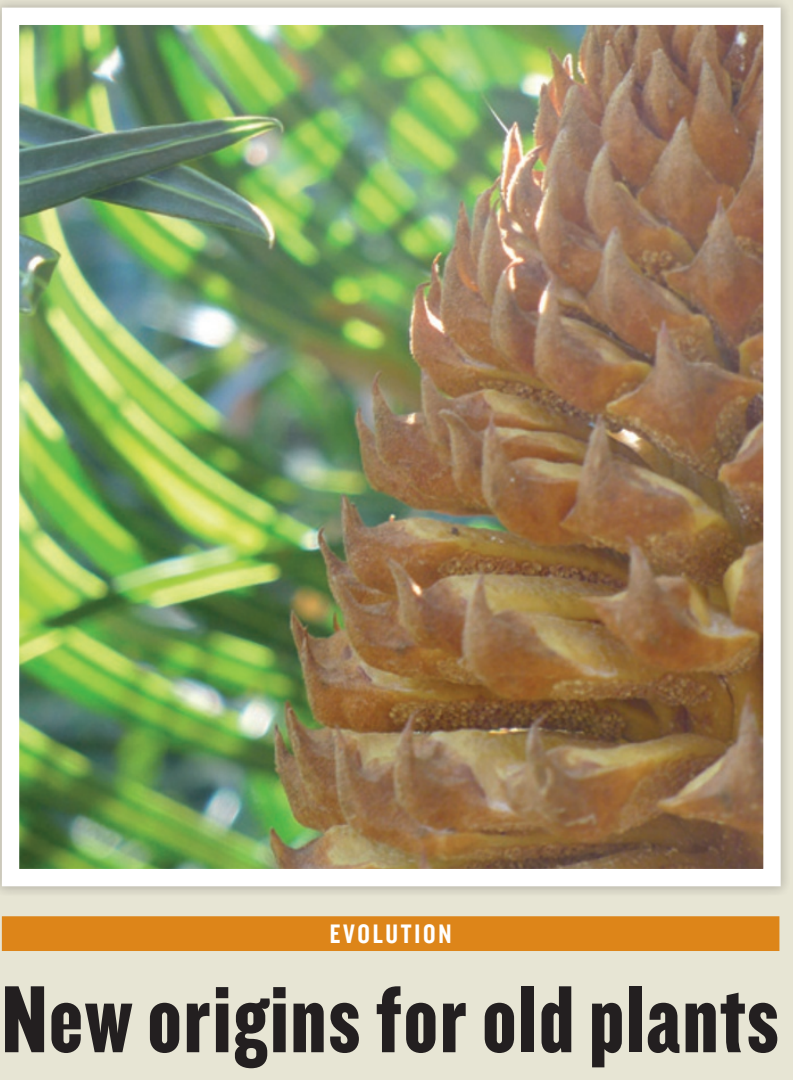

Plants called cycads, which resemble ferns and palms, emerged more than 260 million years ago and are thought to have changed little since. However, today's cycads have more recent roots.

Nathalie Nagalingum at the Royal Botanic Garden Sydney in Australia, Sarah Mathews at Harvard University in Cambridge, Massachusetts, and their team created an evolutionary tree charting the relationships between two-thirds of the world's 300 extant cycad species (one, Cycas thouarsii, pictured). The tree, based on genetic data and fossil records, points to a boom in cycad diversity less than 12 million years ago, during the late Miocene.

A shift to more seasonal climates across the globe during this period may have driven cycad diversification by allowing the plants to expand their range, the authors say.

Science http://dx.doi.org/10.1126/science.1209926 (2011)

The researchers infected 14 monkeys with lethal doses of the virus. They then infused 12 of the animals with two doses of the antibody, which binds to a viral protein used by the virus to attach to host cells. Monkeys injected 10 and 24 hours after infection remained disease-free; those injected after 72 hours exhibited neurological symptoms, but recovered. The two control monkeys died. The team next plans to test this antibody against the closely related, and even more deadly, Nipah virus.

Sci. Transl. Med. 3, 105ra103

(2011)

\section{ECOLOGY}

\section{Predators can kill by presence alone}

No hunting required: simply by being exposed to their prey, predators can prove lethal to them.

Shannon McCauley and her colleagues at the University of Toronto in Canada exposed caged dragonfly larvae (Leucorrhinia intacta) to predators, either fish or another dragonfly species. Survival rates of larvae not exposed to predators were 2.5-4.3 times greater than those of larvae that were exposed.

Another experiment focused on larvae attempting to metamorphose into their adult stage $-11 \%$ of those that had been exposed to fish died in the process, compared with just $2 \%$ of those in a fishfree environment. The authors suggest that increased stress made the exposed dragonflies more vulnerable to other potentially lethal factors. Ecology 92, 2043-2048 (2011)

\section{ASTRONOMY}

\section{Ice in the outer reaches}

A European satellite has detected a reservoir of ice in the dusty outer reaches of a planetary system forming around a nearby ten-millionyear-old star.

Michiel Hogerheijde of the Leiden Observatory in the Netherlands and his colleagues analysed data from the Herschel Space Observatory. From these, they identified a thin layer of water vapour that implies the existence of water ice - several thousand Earth oceans' worth - locked in the ice-coated grains of the circumstellar dust disk. 